\title{
Predictors of smoking cessation in smokers with chronic periodontitis: a 24-month study
}

\section{Gislene INOUE(a) \\ Ecinele Francisca ROSA ${ }^{(a)}$ \\ Elaine Fueta GOMES(a) \\ Mariana Rocha GUGLIELMETTI(a) \\ Priscila CORRAINI(b) \\ Ricardo Koji TAKANO(a) \\ Viviane Lé FERREIRA ${ }^{\text {(a) }}$ \\ Giuseppe Alexandre ROMITO(a) João Paulo Becker LOTUFO(c) \\ Edinalva Tanajura Cruz SOUZA(c) \\ Cláudio Mendes PANNUTI(a)}

(a) Universidade de São Paulo - USP, School of Dentistry, Department of Stomatology, São Paulo, SP, Brazil.

(b)Aarhus University, Department of Clinical Epidemiology, Aarhus, Denmark.

(c) Universidade de São Paulo - USP, University Hospital, São Paulo, SP, Brazil.

Declaration of Interests: The authors certify that they have no commercial or associative interest that represents a conflict of interest in connection with the manuscript.

Corresponding Author:

Cláudio Mendes Pannuti

E-mail: cmpannuti@gmail.com

DOI: 10.1590/1807-3107BOR-2016.vol30.0098

Submitted: Nov 30, 2015

Accepted for publication: May 02, 2016

Last revision: June 08, 2016

\begin{abstract}
The purpose of this 24-month study was to identify predictors of smoking cessation in a cohort of smokers with chronic periodontitis, attending a multidisciplinary smoking cessation program. Of the 286 subjects screened, 116 were included and received non-surgical periodontal treatment and smoking cessation therapy, which consisted of lectures, cognitive behavioral therapy, and pharmacotherapy, according to their individual needs. During initial periodontal treatment, dentists actively motivated the study subjects to stop smoking, using motivational interviewing techniques. Further smoking cessation counseling and support were also provided by the dentists, during periodontal maintenance sessions at 3, 6, 12 and 24 months of follow-up. Smoking status was assessed by means of a structured questionnaire, and was validated by exhaled carbon monoxide (CO) measurements. The Fagerström Test for Cigarette Dependence was used to assess smoking dependence. Of the 61 individuals that remained up to the 24-month examination, 31, 21 and 18 declared that they were not smoking at 3, 12 and 24 months, respectively. Smoking cessation after 24 months was associated with the male gender $(\mathrm{OR}=3.77,95 \% \mathrm{CI}=1.16-12.30)$, baseline $\mathrm{CO}$ levels less than 10ppm (OR $=5.81,95 \% \mathrm{CI} 1.76-19.23)$, not living or working with another smoker $(\mathrm{OR}=7.38,95 \% \mathrm{CI} 1.76-30.98)$ and a lower mean Fagerström test score (OR $=5.63,95 \% \mathrm{CI} 1.55-20.43)$. We concluded that smoking cessation was associated with demographic, smoking history and cigarette dependence variables.
\end{abstract}

Keywords: Smoking; Smoking Cessation; Dentistry; Chronic Periodontitis.

\section{Introduction}

Cigarette smoking is the leading cause of preventable death in the world, mainly in low- and middle-income countries. ${ }^{1}$ Additionally, it is a major risk factor for oral diseases, such as oral cancer ${ }^{2,3}$ and periodontal diseases. ${ }^{4,5,6}$

Smoking cessation is claimed to alleviate the continuing adverse effects of tobacco on periodontal tissues. ${ }^{7}$ A cross-sectional study conducted with a nationally representative U.S. sample showed that former smokers presented a reduced risk of periodontitis, and this risk declined according to the number of years since quitting. ${ }^{8}$ Furthermore, prospective interventional studies have demonstrated that smokers that quit the habit presented 
additional benefits of periodontal clinical treatment, as compared with non-quitters. ${ }^{9,10}$

There is increasing evidence about the role of dental professionals in helping their patients quit tobacco smoking. A number of studies have reported the efficacy of smoking cessation advice delivered by dentists or dental hygienists in a dental setting. 11,12,13,14 A CochraneSystematic Review suggested that tobacco control interventions conducted by oral health professionals could increase smoking abstinence and yield success rates ranging from $2.5 \%$ to $36 \%{ }^{15}$ However, heterogeneity and the limited number of studies have not allowed drawing conclusions about the effectiveness of specific intervention components.

It is important to understand what variables are associated with success in quitting smoking, in order to improve the efficacy of the interventions. Predictors of smoking cessation have been identified in the medical literature. ${ }^{16,17,18}$ However, there is little information about predictors of smoking cessation among dental patients. Thus, the aim of this study was to identify predictors of smoking cessation in a group of chronic periodontitis patients who participated in a multidisciplinary smoking cessation program.

\section{Methodology}

This paper is a secondary publication of the Escape study (NCT02493270), which aimed at verifying the effects of smoking cessation on periodontal clinical parameters. Data regarding the effects of smoking cessation on periodontal clinical parameters are published elsewhere. ${ }^{10,19}$

A prospective interventional study was conducted. Participants were smokers with chronic periodontitis. All of them were willing to quit and enrolled in the smoking cessation clinic at the University Hospital (UH) in São Paulo, Brazil. The study and its protocol were approved by the School of Dentistry Ethics Committee of the University of São Paulo (Protocol No. 29/07). The study subjects were informed of the protocol and signed a written term of free and informed consent before participating in the study.

Every month (from May 2007 to October 2010), a new group of 20 to 30 smokers enrolled in the smoking cessation clinic at the UH. Subjects from these groups were invited to undergo an oral examination and to participate in the study if they met the following inclusion criteria: 1) being a smoker $>18$ years old and willing to stop smoking, 2) having at least 10 teeth in the oral cavity, and 3) presenting with periodontal disease $(30 \%$ or more of the teeth with proximal clinical attachment level $>5 \mathrm{~mm}$ ). ${ }^{20}$ Exclusion criteria were: 1) systemic conditions considered as a risk factors for periodontitis, 2) periodontal treatment in the last 6 months, or 3) continuous use of steroidal or nonsteroidal anti-inflammatory drugs.

After inclusion, the subjects were interviewed and received a complete clinical oral examination at the postgraduate clinic of the Periodontology Department, School of Dentistry, University of São Paulo, located within walking distance (5 minutes) of the UH. A single trained and calibrated examiner (PC) interviewed all the participants using a pretested structured written questionnaire. The following information was collected during the interview: age (in years); sex, occupation, if they could read and write (yes/no), how many years of education they had received, monthly income (in Brazilian Reais), oral and general health information and oral hygiene habits. In addition, questions about their smoking habits asked at the baseline interview included current smoking status (yes or no), length of the habit (in years), type of tobacco consumed, number of cigarettes smoked daily, if they lived or worked with another smoker, number of previous attempts to stop smoking, and the reasons why they started smoking again after quitting. In the remaining follow-up sessions (3, 6, 12 and 24 months), the subjects were asked about their smoking habits in the last 3 months, i.e., if they had successfully stopped smoking, and, if not, the reasons, the number of cigarettes consumed per day, and if they had noticed any changes in their oral and general health since smoking cessation. Reproducibility of the questionnaire was assessed by means of the Kappa coefficient for questions with categorical answers (Kappa coefficients 0.63-0.87), and intraclass correlation coefficient (ICC) for questions with numerical answers (ICC 0.77-0.91).

Participants were also asked about their cigarette dependence, based on the Fagerström Test for Cigarette Dependence, which comprises six questions. ${ }^{21,22}$ In this questionnaire, yes/no answers 
are scored from 0 to 1 and multiple-choice answers are scored from 0 to 3 . The scores are summed to yield a total of $0-10$. The subject's level of cigarette dependence is categorized as very low ( $0-2$ points), low (3-4), moderate (5), high (6-7) or very high (8-10), according to the classification proposed by the developers. We used the Portuguese translation of the Fagerström test, which was validated on a sample of Brazilian smokers in 2002. ${ }^{23}$

Following the interview, a trained and calibrated examiner (EFR) clinically assessed both the dental and periodontal status of all teeth, excluding third molars. The following periodontal clinical parameters were assessed at 6 sites per tooth: probing depth (PD), gingival recession (GR), bleeding on probing (BOP), and visible plaque (yes/no).

Abstinence was confirmed by exhaled carbon monoxide (CO) measurements, which were assessed at baseline and after 3, 6, 12 and 24 months. Measurements were made with a CO monitor (Micro Medical Ltd, Rochester, United Kingdom) by the same examiner who had conducted the interviews. The cut-off point adopted to distinguish smokers from nonsmokers was 8 ppm. ${ }^{24}$

After the initial examination, all subjects received non-surgical periodontal therapy by three periodontists. After the initial phase of the periodontal treatment, comprising 4 to 6 sessions, the subjects entered a maintenance program, with a three-month interval between appointments.

The smoking cessation therapy was performed at the smoking cessation clinic at the University Hospital $(\mathrm{UH})$, and was provided by a multidisciplinary team comprising physicians, psychologists, nurses, a pharmacist and a dentist. The therapy consisted of four consecutive lectures (one per week with a mean duration of one hour each), given by a physician (J.P.B.L) and a dentist (G.I.). The lectures were intended to counsel subjects about the detrimental effects of smoking on general health (cancer, cardiovascular diseases, etc.) and oral health (halitosis, dental stains, oral cancer, periodontal disease, etc.), as well as the benefits of quitting the habit. Furthermore, participants received psychologist-assisted (E.T.C.S.) cognitive behavioral therapy, according to individual needs, up to 1 year after initiating the therapy.
In addition, participants received pharmacotherapy, which consisted of Nicotine Replacement Therapy (NRT) and medication, according to their individual needs and as judged by the medical team. NRT consisted of Niquitin patches of 21, 14, or $7 \mathrm{mg}$ /day (GlaxoSmithKline Brasil Ltda., Rio de Janeiro, Brazil), and/or Nicorette gum of $4 \mathrm{mg}$ (Johnson \& Johnson do Brasil, São José dos Campos, Brazil) according to their cigarette dependence. Some of the participants were also prescribed bupropion (GlaxoSmithKline Brasil Ltda., Rio de Janeiro, Brazil) or varenicline (Pfizer Ltda., Guarulhos, Brazil), for controlling abstinence symptoms.

During initial periodontal treatment, the interviewer and the dentists actively motivated the study subjects to stop smoking, using motivational interviewing techniques. ${ }^{25}$ Further smoking cessation counseling and support were provided by the dentists who performed the periodontal maintenance sessions at 3, 6 and 12 months of follow-up, in order to prevent relapse.

All written data were converted into electronic form using data entry software (Epidata 3.1, Odense, Denmark). Statistical analysis was performed using Stata 10.1 (Stata Corporation, College Station, TX, USA).

The smoking cessation frequencies were calculated after 3, 6, 12 and 24 months of follow-up. Quitters were defined as those who answered "no" to the question "Are you smoking?", which was validated with the expired CO measurements (cut-off point of $8 \mathrm{ppm}$ ). According to this question, participants were classified as quitters or non-quitters. Oscillators (subjects who stopped smoking during the study but relapsed) were included with non-quitters in the statistical analysis. The two groups were compared in respect to categorical variables using the chi-square test. Differences between groups were assessed by means of Student's t-test. A significance level of alpha $=5 \%$ was used in all the statistical tests.

A univariate logistic regression analysis was conducted to assess the predictive value of the demographic variables, measures of smoking history and measures of cigarette dependence for successful quitting at the 24-month examination. This analysis was conducted with the 61 subjects who remained up to the 24-month examination. A multiple regression analysis was not performed, due to the small sample size. 


\section{Results}

A total of 1144 subjects applied to participate in the smoking cessation program at the University Hospital from May 2007 to October 2010. All of them were invited to undergo the oral examination, but only 286 agreed and were examined. One hundred and sixteen (116) fulfilled the eligibility criteria and were included in the investigation. The subjects included 34 men and 82 females with a mean age of 48.3+7.1 years. Most of them had made previous attempts to quit, and the most common reasons for relapse were: anxiety ( $\mathrm{n}=39)$, living/working or friendship with smokers $(n=9)$, depression $(n=3)$, habit $(\mathrm{n}=5)$, personal or family problems $(\mathrm{n}=4)$, stress $(n=7)$, and withdrawal symptoms $(n=10)$.

All subjects included received non-surgical periodontal treatment and smoking cessation therapy. Losses to follow-up were as follows: 27 between baseline and 3 - months, 11 between 3 and 6 months, 10 between 6 and 12 months, and 07 between 12 and 24 months. Of the 61 individuals that remained up to the 24-month examination, 31, 21 and 18 declared that they were not smoking at 3, 12 and 24 months, respectively. The self-reported smoking status was compared with the expired $\mathrm{CO}$ values, and none of the subjects who reported quitting smoking presented an expired $\mathrm{CO}$ value $>8 \mathrm{ppm}$. At the 12-month examination, 21 subjects were quitters. One of them was smoking at the 24-month examination and the other two were lost to follow-up. All of the 18 subjects who reported not smoking at the 24-month examination also declared not smoking at the 12-month examination.

Table 1 presents the demographic and periodontal clinical characteristics of the 61 subjects that remained up to the 12-month examination, and the 55 individuals who were lost to follow-up. There was no significant statistical difference between quitters and non-quitters as regards age, years of education, income and clinical periodontal variables. However, there was a significant association between gender and smoking cessation $(p=0.02)$. Subjects who were lost to follow-up were significantly younger than participants who were present at the 24-month examination $(p=0.004)$.

Table 2 shows the smoking characteristics of the subjects. Quitters presented lower CO levels $(p=0.03$ ) than non-quitters. There was an association between smoking cessation and coexistence (living or working) with another smoker $(p=0.003)$. Moreover, quitters presented lower Fagerström test scores $(p=0.04)$.

Univariate regression analysis revealed that the factors significantly associated with smoking cessation after 24 months (Table 3) were the male gender (OR = 3.77, IC 95\% 1.16-12.30), CO measurement at baseline less than $10 \mathrm{ppm}(\mathrm{OR}=5.81,95 \% \mathrm{CI} 1.76-19.23)$,

Table 1. Baseline demographic and periodontal clinical characteristics of non-quitters (smokers and oscillators combined) $(n=43)$, quitters $(n=18)$ and subjects lost after 24 months of follow-up $(n=55)$.

\begin{tabular}{|c|c|c|c|c|c|c|}
\hline Parameters & $\begin{array}{l}\text { Non-quitters } \\
(n=43)\end{array}$ & $\begin{array}{l}\text { Quitters } \\
(n=18)\end{array}$ & $p$ value & $\begin{array}{c}\text { Total } \\
(n=61)\end{array}$ & $\begin{array}{l}\text { Lost to follow-up } \\
\quad(n=55)\end{array}$ & $\mathrm{p}$ value \\
\hline \multicolumn{7}{|l|}{ Demographic variables } \\
\hline Mean (SD) age (years) & $49.8(7.5)$ & $49.4(7.0)$ & 0.98 & $49.6(7.3)$ & $45.7(8.4)$ & $0.004^{*}$ \\
\hline Gender, $\%$ male & 9 (20.9\%) & $9(50.0 \%)$ & $0.02^{*}$ & 18 (29.5\%) & $16(29.1 \%)$ & 0.57 \\
\hline Mean (SD) years of education & $11.3(5.3)$ & $11.8(4.3)$ & 0.74 & $11.4(5.0)$ & $10.2(4.4)$ & 0.17 \\
\hline $\begin{array}{l}\text { Mean (SD) monthly income, in Brazilian } \\
\text { reais }\end{array}$ & $\begin{array}{c}1712.2 \\
(1520.9)\end{array}$ & $\begin{array}{l}1840.0 \\
(1214.7)\end{array}$ & 0.78 & $\begin{array}{c}1749.9 \\
(1426.7)\end{array}$ & $\begin{array}{c}1313.1 \\
(1080.0)\end{array}$ & 0.08 \\
\hline \multicolumn{7}{|l|}{ Periodontal variables } \\
\hline Mean (SD) number of teeth present & $20.2(5.0)$ & $20.4(4.7)$ & 0.97 & $20.3(4.9)$ & $19.0(4.5)$ & 0.18 \\
\hline Mean (SD) \% sites visible plaque & $\begin{array}{l}83.3 \% \\
(16.6)\end{array}$ & $91.8 \%(7.6)$ & 0.69 & $85.8(13.9)$ & $86.2(25.0)$ & 0.44 \\
\hline Mean (SD) CAL (mm) & $4.1(1.1)$ & $4.0(0.8)$ & 0.91 & $4.1(1.0)$ & $4.4(0.9)$ & 0.34 \\
\hline Mean (SD) PD (mm) & $2.9(0.7)$ & $2.9(0.6)$ & 0.98 & $2.9(0.7)$ & $3.3(0.7)$ & 0.06 \\
\hline Mean (SD) \% sites BoP & $20.9(12.3)$ & $28.1 \%(20.9)$ & 0.63 & $23.0(14.8)$ & $30.3(18.1)$ & 0.17 \\
\hline
\end{tabular}

${ }^{*}$ significant at alpha $=5 \%$. 
Table 2. Baseline smoking characteristics of non-quitters (smokers and oscillators combined) $(n=43)$, quitters $(n=18)$ and subjects lost after 2 years of follow-up $(n=55)$.

\begin{tabular}{|c|c|c|c|c|c|c|}
\hline Parameters & $\begin{array}{l}\text { Non-quitters } \\
(n=43)\end{array}$ & $\begin{array}{l}\text { Quitters } \\
(n=18)\end{array}$ & p value & $\begin{array}{c}\text { Total } \\
(\mathrm{n}=61)\end{array}$ & $\begin{array}{l}\text { Lost to follow-up } \\
\qquad(\mathrm{n}=55)\end{array}$ & $\mathrm{p}$ value \\
\hline \multicolumn{7}{|l|}{ Measures of smoking history } \\
\hline Smoking, mean number of packs / day & $1.2(0.6)$ & $1.1(0.4)$ & 0.70 & $1.2(0.5)$ & $1.0(0.5)$ & 0.06 \\
\hline Mean (SD) number of years smoking & $33.3(8.7)$ & $33.6(5.5)$ & 0.89 & $33.4(7.8)$ & $28.2(8.5)$ & $0.001^{*}$ \\
\hline Mean (SD) age started smoking & $16.7(4.3)$ & $16.4(4.1)$ & 0.81 & $16.6(4.2)$ & $17.5(5.1)$ & 0.30 \\
\hline Mean (SD) exhaled CO reading (ppm) & $16.7(11.3)$ & $12.8(12.7)$ & $0.03^{*}$ & $15.5(11.7)$ & $20.4(12.1)$ & $0.04^{*}$ \\
\hline Live or work with a smoker & 24 (55.8\%) & $03(16.7 \%)$ & $0.003^{*}$ & 27 (44.2\%) & $13(23.6 \%)$ & $0.03^{*}$ \\
\hline $\begin{array}{l}\text { Use of NRT or medication in smoking } \\
\text { cessation therapy }\end{array}$ & $14(32.5 \%)$ & $08(44.4 \%)$ & 0.37 & $22(36.0 \%)$ & $23(41.8 \%)$ & 0.65 \\
\hline \multicolumn{7}{|l|}{ Measures of nicotine dependence } \\
\hline Mean (SD) number of previous attempts to quit & $1.8(1.7)$ & $2.1(1.6)$ & 0.49 & $1.9(1.7)$ & $2.0(1.9)$ & 0.84 \\
\hline \multicolumn{7}{|l|}{ Level of dependence ${ }^{*}$ (Fagerström) } \\
\hline Very low & $2(4.9 \%)$ & $2(11.8 \%)$ & 0.10 & $4(7.0 \%)$ & $4(7.5 \%)$ & 0.65 \\
\hline Low & $6(14.7 \%)$ & 7 (41.2\%) & & $13(22.4 \%)$ & $8(15.1 \%)$ & \\
\hline Moderate & $7(17.0 \%)$ & $4(23.5 \%)$ & & $11(19.0 \%)$ & $8(15.1 \%)$ & \\
\hline High & 21 (51.2\%) & $4(23.5 \%)$ & & $25(43.0 \%)$ & $23(43.4 \%)$ & \\
\hline Very high & $5(12.2 \%)$ & $0(0.0 \%)$ & & $5(8.6 \%)$ & $10(18.9 \%)$ & \\
\hline Mean (SD) Fagerström Test ${ }^{*}$ Score & $5.5(2.0)$ & $4.3(1.9)$ & $0.04^{*}$ & $5.2(2.1)$ & $5.7(2.4)$ & 0.20 \\
\hline
\end{tabular}

*significant at alpha $=5 \%$; ${ }^{\ddagger} 2$ missing values for non-quitters, 1 missing value for quitters and 2 missing values for lost to follow-up.

no coexistence with another smoker $(\mathrm{OR}=7.38,95 \% \mathrm{CI}$ 1.76-30.98) and scoring 5 or less on the Fagerström test $(\mathrm{OR}=5.63,95 \% \mathrm{CI} 1.55-20.43)$.

\section{Discussion}

The findings of this study revealed that the male gender, lower $\mathrm{CO}$ levels at baseline, no coexistence with another smoker, and lower cigarette dependence were predictive of 24-month smoking abstinence. At the end of the study, 18 subjects (29.5\% of the sample) were not smoking. The majority of the studies in the dental literature followed up participants for 12 months, and presented smoking cessation rates of $11 \%,{ }^{12} 25 \%$ and $36.4 \%{ }^{13}$. Nohlert et al..$^{14}$ observed a $36 \%$ prevalence of abstinence after 12 months, further reduced to $27 \%$ after 24 months. It is noteworthy that a high initial cessation rate was observed in all investigations, but that the percentage of quitters tended to decrease over time.

In the present study, we observed that men were more likely to quit smoking than women. These findings are in accordance with many reports from the medical literature, which shows that women are more likely to maintain their smoking behavior. ${ }^{26,27,28,29}$ Some of the possible reasons are greater concerns about weight gain, more difficulty to cope with a negative mood associated with abstinence, and greater need for social support to quit, as compared with men $^{30}$. Moreover, women present higher smoking behavioral dependence than men, whereas males present higher cigarette dependence than females ${ }^{28}$, suggesting that smoking cessation programs should be tailored to gender, with greater emphasis on behavioral compensation for women and nicotine replacement for men.

The authors also observed that expired CO levels were associated with successful quitting. Interestingly, the mean number of cigarette packs consumed per year was not a predictor of quitting. This could be explained by the fact that cigarette consumption is often underestimated when it is based on self-reported data. ${ }^{31}$ In contrast, biochemical measurements of smoking behavior are considered objective and accurate. ${ }^{23}$ Measurements of exhaled CO levels are a non-invasive, practical and low-cost method used in many smoking cessation trials because of its accuracy and reproducibility ${ }^{32,33}$. 
In the present study, living or working with a smoker was the most important predictor of smoking cessation. We grouped "living with a smoker" together with "working with a smoker" in the same category, because of the small sample size. There is little information in the literature regarding the effect of working with smokers on the success of quitting. However, some investigations observed that a relationship or friendship with a smoker negatively affects the chance of quitting. The ATTEMPT cohort study $^{34}$ observed that participants who tried to quit in the presence of other smokers were more likely to relapse, as compared with those who did not. A recent systematic review of smoking cessation

Table 3. Predictors related to smoking cessation among the 18 quitters and 43 non-quitters who remained up to the 24 -month examination: univariate analysis.

\begin{tabular}{|c|c|c|}
\hline Variable & OR $(95 \% \mathrm{Cl})$ & $p$-value \\
\hline \multicolumn{3}{|l|}{ Demographic variables } \\
\hline \multicolumn{3}{|l|}{ Age } \\
\hline (ref. cat.) $\leq 50$ years & 1.00 & 0.88 \\
\hline$>50$ years & $0.92(0.30-2.78)$ & \\
\hline \multicolumn{3}{|l|}{ Gender } \\
\hline (ref. cat.) Female & 1.00 & $0.02^{*}$ \\
\hline Male & $3.77(1.16-12.30)$ & \\
\hline \multicolumn{3}{|l|}{ Years of education } \\
\hline (ref. cat.) $<10$ years & 1.00 & 0.60 \\
\hline 10 years or more & $1.38(0.40-4.69)$ & \\
\hline \multicolumn{3}{|l|}{ Monthly income, in Brazilian reais } \\
\hline (ref. cat.) $<1000$ reais & 1.00 & 0.34 \\
\hline 1000 Reais or more & $2.00(0.47-8.46)$ & \\
\hline \multicolumn{3}{|l|}{ Measures of smoking history } \\
\hline \multicolumn{3}{|l|}{ Number of packs / day at baseline } \\
\hline (ref. cat.) 1 pack or more & 1.00 & 0.34 \\
\hline Less than 1 pack & $0.36(0.04-3.25)$ & \\
\hline \multicolumn{3}{|l|}{ Age started smoking } \\
\hline (ref. cat.) 14 years or less & 1.00 & 0.21 \\
\hline Older than 14 years & $0.48(0.15-1.51)$ & \\
\hline \multicolumn{3}{|l|}{ Exhaled CO reading (ppm) at baseline } \\
\hline (ref. cat.) $10 \mathrm{ppm}$ or more & 1.00 & $0.003^{*}$ \\
\hline Less than 10 ppm & $5.81(1.76-19.23)$ & \\
\hline \multicolumn{3}{|l|}{ Live or work with a smoker } \\
\hline (ref. cat.) Yes & 1.00 & $0.003^{*}$ \\
\hline No & $7.38(1.76-30.98)$ & \\
\hline \multicolumn{3}{|c|}{ Use of pharmacotherapy (NRT or medication) in smoking cessation therapy } \\
\hline (ref. cat.) No & 1.00 & 0.37 \\
\hline Yes & $1.58(0.49-5.04)$ & \\
\hline \multicolumn{3}{|l|}{ Measures of cigarette dependence } \\
\hline \multicolumn{3}{|l|}{ Previous attempts to quit } \\
\hline (ref. cat.) No & 1.00 & 0.64 \\
\hline Yes & $1.35(0.37-4.95)$ & \\
\hline \multicolumn{3}{|l|}{ Level of dependence $¥$ (Fagerström) } \\
\hline (ref. cat.) 6 or more (high / very high) & 1.00 & $0.006^{*}$ \\
\hline 5 or less (very low / low / moderate) & $5.63(1.55-20.43)$ & \\
\hline
\end{tabular}

${ }^{¥} 2$ missing values for non-quitters, 1 missing value for quitters. 
among adolescents and young smokers has identified an association of successful smoking cessation with not having friends who smoke. ${ }^{17}$ It is recognized that smokers are inclined to associate with friends who also smoke, whereas nonsmokers prefer to relate with other nonsmokers. ${ }^{35}$ The influence of friends or colleagues who smoke may trigger relapse, since these individuals may consciously or unconsciously encourage the quitter to start smoking again.

Marital relationship is regarded as one of the most important factors that influence health behaviors. Accordingly, a partner's smoking status is an important predictor of smoking cessation. Smoking cessation of married subjects is more likely if the partner also quits, ${ }^{36}$ and a smoker whose partner is a nonsmoker or has quit smoking is more likely to quit. ${ }^{37}$ This may be explained by the direct and indirect social control within the couple, behavioral diffusion and sharing of the same environment.

In our study, Fagerström test scores of 5 or less (very low to moderate cigarette dependence) were associated with successful smoking cessation. This association has been consistently observed in the medical literature. ${ }^{18,29,34,38}$ Two systematic reviews ${ }^{16,17}$ have observed that lower cigarette dependence predicted the success of an attempt to quit. We used the Portuguese version ${ }^{23}$ of the Fagerström Test for Cigarette Dependence ${ }^{22}$ to measure dependence. The Portuguese adaptation of the questionnaire presents a high level of reliability and validity, like the original version. Since there is no cost incurred in using the Fagerström test, our results support the use of this instrument by dentists in their clinical setting, in order to identify highly dependent smokers.

\section{References}

1. World Health Organization [homepage]. Geneva: World Health Organization; 2011 [cited 2014 Jul 17]. Available from: http:// whqlibdoc.who.int/publications/2011/9789240687813_eng.pdf

2. Warnakulasuriya S, Sutherland G, Scully C. Tobacco, oral cancer, and treatment of dependence. Oral Oncol. 2005;41(3):244-60. doi:10.1016/j.oraloncology.2004.08.010

3. Gandini S, Botteri E, Iodice S, Boniol M, Lowenfels AB, Maisonneuve $P$ et al. Tobacco smoking and cancer: a metaanalysis. Int J Cancer. 2008;122(1):155-64. doi:10.1002/ijc.23033
Limitations of this study include the relative small sample size and the lack of a control group. We have also observed a high attrition rate, since nearly half of the subjects were lost to follow-up after two years. However, high drop-out rates are a frequent finding in dental ${ }^{9}$ and medical smoking cessation studies ${ }^{34}$, and may be a result of low morale observed in smoking cessation program participants. There is evidence that some of the participants may develop negative affective states during this phase, ranging from depression to an increased risk for suicide. ${ }^{39}$

The strengths of the study include its prospective design, validation of abstinence using a CO monitor, and long follow-up period (24 months). The Russell Standard suggests 6 or 12 months as the minimum length of time for assessing tobacco abstinence. ${ }^{40}$ Interestingly, in our study, most of the subjects who were not smoking at the 12-month examination managed to remain as quitters up to the 24-month examination, which corroborates data from Nohlert et al. ${ }^{14}$ Whereas longer follow-up periods may be necessary to observe the effects of smoking cessation on periodontal tissues and tooth loss, the 12-month follow-up of participants may be sufficient to assess the efficacy of smoking cessation interventions on quitting rates.

\section{Conclusion}

Smoking cessation was associated with demographic, smoking history and nicotine dependence variables.

\section{Acknowledgments}

This study was supported by a grant from FAPESP (07/54494-3).

4. Lima FR, Cesar-Neto JB, Lima DR, Kerbauy WD,

Nogueira-Filho GR. Smoking enhances bone loss in anterior teeth in a Brazilian population: a retrospective cross-sectional study. Braz Oral Res. 2008;22(4):328-33. doi:10.1590/S1806-83242008000400008

5. Corraini P, Baelum V, Pannuti CM, Pustiglioni AN, Romito GA, Pustiglioni FE. Risk indicators for increased probing depth in an isolated population in Brazil. J Periodontol. 2008;79(9):1726-34. doi:10.1902/jop.2008.070586 
6. Haas AN, Wagner MC, Oppermann RV, Rösing CK, Albandar JM, Susin C. Risk factors for the progression of periodontal attachment loss: a 5-year population-based study in South Brazil. J Clin Periodontol. 2014;41(3):215-23. doi:10.1111/jcpe.12213

7. César Neto JB, Rosa EF, Pannuti CM, Romito GA. Smoking and periodontal tissues: a review. Braz Oral Res. 2012;26 (n espel 1):25-31. doi:10.1590/S1806-83242012000700005

8. Tomar SL, Asma S. Smoking-attributable periodontitis in the United States: findings from NHANES III. National Health and Nutrition Examination Survey. J Periodontol. 2000;71(5):743-51. doi:10.1902/jop.2000.71.5.743

9. Preshaw PM, Heasman L, Stacey F, Steen N, McCracken GI, Heasman PA. The effect of quitting smoking on chronic periodontitis. J Clin Periodontol. 2005; 32(8):869-79. doi:10.1111/j.1600-051X.2005.00779.x

10. Rosa EF, Corraini P, Carvalho VF, Inoue G, Gomes EF, Lotufo JP et al. A prospective 12-month study of the effect of smoking cessation on periodontal clinical parameters. J Clin Periodontol. 2011;38(6):562-71. doi:10.1111/j.1600-051X.2011.01723.x

11. Nasry HA, Preshaw PM, Stacey F, Heasman L, Swan M, Heasman PA. Smoking cessation advice for patients with chronic periodontitis. Br Dent J. 2006;200(5):272-5. doi:10.1038/sj.bdj.4813307

12. Binnie VI, McHugh S, Jenkins W, Borland W, Macpherson LM. A randomised controlled trial of a smoking cessation intervention delivered by dental hygienists: a feasibility study. BMC Oral Health 2007;7(1):5. doi:10.1186/1472-6831-7-5

13. Hanioka T, Ojima M, Tanaka H, Naito M, Hamajima N, Matsuse R. Intensive smoking-cessation intervention in the dental setting. J Dent Res. 2010;89(1):66-70. doi:10.1177/0022034509350867

14. Nohlert E, Öhrvik J, Tegelberg Å, Tillgren P, Helgason ÁR. Long-term follow-up of a high- and a low-intensity smoking cessation intervention in a dental setting--a randomized trial. BMC Public Health. 2013;13(1):592. doi:10.1186/1471-2458-13-592

15. Carr AB, Ebbert J. Interventions for tobacco cessation in the dental setting. Cochrane Database Syst Rev. 2012;(1):CD005084. doi:10.1002/14651858.CD005084.pub3

16. Vangeli E, Stapleton J, Smit ES, Borland R, West R. Predictors of attempts to stop smoking and their success in adult general population samples: a systematic review. Addiction. 2011;106(12):2110-21. doi:10.1111/j.1360-0443.2011.03565.x

17. Cengelli S, O'Loughlin J, Lauzon B, Cornuz J. A systematic review of longitudinal population-based studies on the predictors of smoking cessation in adolescent and young adult smokers. Tob Control. 2012;21(3):355-62. doi:10.1136/tc.2011.044149

18. Kale D, Gilbert HM, Sutton S. Are predictors of making a quit attempt the same as predictors of 3-month abstinence from smoking? Findings from a sample of smokers recruited for a study of computer-tailored smoking cessation advice in primary care. Addiction. 2015;110(10):1653-64. doi:10.1111/add.12972

19. Rosa EF, Corraini P, Inoue G, Gomes EF, Guglielmetti MR, Sanda SR et al. Effect of smoking cessation on non-surgical periodontal therapy: results after 24 months. J Clin Periodontol. 2014;41(12):1145-53. doi:10.1111/jcpe.12313

20. Tonetti MS, Claffey N. Europeans workshop in Periodontology group C. Advances in progression of periodontitis and proposal of definitions of a periodontitis case and disease progression for use in risk factors research. Group C consensus reporto of the 5th European Workshop in Periodontology. J Clin Periodontol. 2005;32(Suppl 6):210-3. doi:10.1111/j.1600-051X.2005.00822.x

21. Heatherton TF, Kozlowski LT, Frecker RC, Fagerström KO. The Fagerström test for nicotine dependence: a revision of the Fagerström tolerance questionnaire. Br J Addict. 1991;86(9):1119-27. doi:10.1111/j.1360-0443.1991.tb01879.x

22. Fagerström K. Determinants of tobacco use and renaming the FTND to the Fagerstrom Test for Cigarette Dependence. Nicotine Tob Res. 2012;14(1):75-8. doi:10.1093/ntr/ntr137

23. Do Carmo JT, Pueyo AA. A adaptação ao português do Fagerström test for nicotine dependence (FTND) para avaliar a dependência e tolerância à nicotina em fumantes brasileiros. Rev Bras Med. 2002;59:73-80. doi:10.1080/14622200210123581

24. Benowitz NL, Iii PJ, Ahijevych K, Jarvis MJ, Hall S, LeHouezec J et al. Biochemical verification of tobacco use and cessation. Nicotine Tob Res. 2002;4(2):149-59.

25. Miller WR, Rollnick S. Motivational interviewing: preparing people for change. 2nd ed. New York: Guilford; 2002.

26. Hymowitz N, Cummings KM, Hyland A, Lynn WR, Pechacek TF, Hartwell TD. Predictors of smoking cessation in a cohort of adult smokers followed for five years. Tob Control. 1997;6(suppl 2):S57-62. doi:10.1136/tc.6.suppl_2.S57

27. Osler M, Prescott E, Godtfredsen N, Hein HO, Schnohr P. Gender and determinants of smoking cessation: a longitudinal study. Prev Med. 1999;29(1):57-62. doi:10.1006/pmed.1999.0510

28. Bohadana A, Nilsson F, Rasmussen T, Martinet Y. Gender differences in quit rates following smoking cessation with combination nicotine therapy: influence of baseline smoking behavior. Nicotine Tob Res. 2003;5(1):111-6. doi:10.1080/1462220021000060482

29. Iliceto P, Fino E, Pasquariello S, D'Angelo Di Paola ME, Enea D. Predictors of success in smoking cessation among Italian adults motivated to quit. J Subst Abuse Treat. 2013;44(5):534-40. doi:10.1016/j.jsat.2012.12.004

30. Jensvold MF, Halbreich U, Hamilton JA. Psychopharmacology and women: Sex, gender, and hormones. Washington, DC: American Psychiatric Press; 1996. 
31. Connor Gorber S, Schofield-Hurwitz S, Hardt J, Levasseur G, Tremblay M. The accuracy of self-reported smoking: a systematic review of the relationship between self-reported and cotinine-assessed smoking status. Nicotine Tob Res. 2009;11(1):12-24. doi:10.1093/ntr/ntn010

32. Scott DA, Palmer RM, Stapleton JA. Validation of smoking status in clinical research into inflammatory periodontal disease. J Clin Periodontol. 2001;28(8):715-22 doi:10.1034/j.1600-051X.2001.280801.x

33. Frei M, Engel Brügger O, Sendi P, Reichart PA, Ramseier CA, Bornstein MM. Assessment of smoking behaviour in the dental setting. A study comparing self-reported questionnaire data and exhaled carbon monoxide levels. Clin Oral Investig. 2012;16(3):755-60. doi:10.1007/s00784-011-0583-2

34. Zhou X, Nonnemaker J, Sherrill B, Gilsenan AW, Coste F, West R. Attempts to quit smoking and relapse: factors associated with success or failure from the ATTEMPT cohort study. Addict Behav. 2009;34(4):365-73. doi:10.1016/j.addbeh.2008.11.013

35. Abreu MN, Caiaffa WT. [Influence of family environment and social group on smoking among Brazilian youth aged
15 to 24 years]. Rev Panam Salud Publica. 2011;30(1):22-30. doi:10.1590/S1020-49892011000700004

36. Falba TA, Sindelar JL. Spousal concordance in health behavior change. Health Serv Res. 2008;43(1 Pt 1):96-116. doi:10.1111/j.1475-6773.2007.00754.x

37. Margolis R, Wright L. Better off alone than with a smoker: the influence of Partner's Smoking Behavior in Later Life. J Gerontol B Psychol Sci Soc Sci. 2015;pii:gbu220. doi:10.1093/geronb/gbu220

38. Hyland A, Borland R, Li Q, Yong HH, McNeill A, Fong GT et al. Individual-level predictors of cessation behaviours among participants in the International Tobacco Control (ITC). Four Country Survey. Tob Control. 2006;15(Suppl 3):83-94.

39. Thorndike AN, Regan S, McKool K, Pasternak RC, Swartz $\mathrm{S}$, Torres-Finnerty $\mathrm{N}$ et al. Depressive symptoms and smoking cessation after hospitalization for cardiovascular disease. Arch Intern Med. 2008;168(2):186-91. doi:10.1001/archinternmed.2007.60

40. West R, Hajek P, Stead L, Stapleton J. Outcome criteria in smoking cessation trials: proposal for common standard. Addiction. 2005;100(3):299-303. doi:10.1111/j.1360-0443.2004.00995.x 